\title{
UN EJEMPLO PRÁCTICO DE APLICACIÓN OPERATIVA DE LA TELEDETECCIÓN A LA GESTIÓN DE RIESGOS NATURALES: CARTOGRAFÍA Y EVALUACIÓN URGENTE DE ÁREAS QUEMADAS EN GALICIA
}

\author{
M. P. MARTÍN ISABEL ${ }^{(1,3)}$, E. CHUVIECO SALINERO(2,3), P. OLIVA PAVÓN ${ }^{(2)}$ \\ F. RODRÍGUEZ-VERDÚ ${ }^{(2)}$ H. NIETO SOLANA ${ }^{(2)}$ y D. PADRÓN PAREDES(2)
}

(1) Instituto de Economía, Geografía y Demografía. Centro de Ciencias Humanas y Sociales. C/ Albasanz, 26-28, Madrid 28037

(2) Departamento de Geografía (Universidad de Alcalá) C/ Colegios, 2, Alcalá de Henares (Madrid) 28002

(3) Unidad Asociada GEOLAB (CSIC-UA)

Correo electrónico de contacto: mpilar.martin@ieg.csic.es

RESUMEN. En este artículo se muestra la capacidad operativa de la teledetección para responder de forma casi inmediata a la demanda de información en una situación de crisis generada por los incendios forestales que afectaron a Galicia en agosto de 2006. La interpretación visual de imágenes obtenidas por los satélites AQUA/ TERRA-MODIS, con una resolución espacial de 500 y 250 metros, permitió cartografiar las zonas afectadas y obtener una rápida evaluación de los daños, incluyendo una estimación de los niveles de severidad de las áreas quemadas. Las imágenes procedentes del sensor IRS-AWiFS, de mayor resolución espacial (60 metros), facilitaron una evaluación y delimitación más precisa de las áreas quemadas. La información generada fue difundida a gestores, investigadores y público en general mediante una página web y un servidor cartográfico diseñado a tal efecto.

ABSTRACT. This paper presents an example of potential uses of remote sensing $(R S)$ data to provide operational information for natural hazards management. It shows how RS was used to provide update information to evaluate the impacts of a large sequence of forest fires that took place in Galician in August 2006. Through visual interpretation of both AQUA/ TERRA-MODIS images, with 250 and $500 \mathrm{~m}$ spatial resolution, fire affected zones were mapped and burn severity levels were estimated. Images from IRS-AWiFS sensor with higher spatial resolution $(60 \mathrm{~m})$ were used as well to evaluate and map burned areas with higher accuracy. The information generated from satellite data was disseminate 
to fire managers, researchers and general public through a web site using a map server which was designed specifically for this purpose.

Palabras clave: AQUA/ TERRA-MODIS, cartografía de incendios, gestión de riesgos, análisis visual.

Key-Words: AQUA/ TERRA-MODIS, burnt land mapping, risk management, visual analysis.

Enviado el 10 de junio de 2007

Aceptado el 30 de septiembre de 2007

\section{Introducción}

La teledetección se ha convertido en los últimos años en una herramienta casi imprescindible para la planificación y gestión territorial a diversas escalas. Un ejemplo de especial relevancia por su repercusión ambiental y social es la gestión de riesgos naturales (inundaciones, terremotos, incendios, etc.). Diversos equipos de investigación a nivel nacional e internacional trabajan actualmente en el desarrollo de métodos que permitan la predicción, gestión y cartografía de riesgos naturales a partir de la teledetección espacial (Valcarce et al., 2007). El objetivo es ofrecer información rápida y precisa de cara a evitar o atenuar los efectos sobre la población, las infraestructuras y el medioambiente. La mayor parte de los riesgos naturales son susceptibles de ser analizados a partir de teledetección, ya sea en la fase de prevención, en la gestión de la crisis o en la evaluación y recuperación de las zonas afectadas. La gran diversidad de sensores (aeroportados y espaciales) actualmente disponibles y el amplio rango de características espectrales, espaciales y temporales que presentan, ofrecen una amplia gama de fuentes de información útiles al gestor (Lentile et al., 2006).

En el ámbito de los incendios forestales, la cartografía del número, localización y área afectada resulta especialmente útil de cara a disponer de información suficiente para realizar un análisis apropiado de la distribución espacial de este fenómeno (Arino et al., 2001). Este tipo de análisis permite extraer conclusiones acerca del grado de actividad de cada una de las variables que en él intervienen, además de mostrar la sensibilidad al fuego que presentan las diferentes regiones (Lee et al., 2006; Verdú, 2007). En este aspecto, la teledetección constituye una inestimable fuente de información de cara a la prevención (localización de medios en áreas de fuerte incidencia histórica, validación de modelos de riesgo, etc.) y gestión de las áreas afectadas por incendios, con el propósito de conseguir una adecuada recuperación de las mismas (Lentile et al., 2006). La posibilidad que ofrece la teledetección para obtener esta información en tiempo "casi real" facilita, además, las labores de evaluación de daños de cara a determinar rápidamente las zonas con mayor vulnerabilidad potencial post-incendio, priorizando las tareas de defensa y recuperación que permitan minimizar las pérdidas ambientales y las consecuencias sociales que de ellas puedan derivarse. 
Los incendios que arrasaron Galicia en los primeros días de agosto de 2006 generaron una situación de crisis que demandaba información rápida y precisa sobre el desarrollo del fenómeno, de cara a una evaluación inmediata de los daños ocasionados. Este período de intensa ocurrencia estuvo precedido por una situación meteorológica muy desfavorable, con fuerte sequía acumulada que coincidió con vientos del noreste que soplaban en la región desde finales de julio y que arreciaron a partir del 4 de agosto. Esta situación de meteorología adversa estuvo acompañada de una intensa actividad incendiaria, con la aparición de cientos de focos cada día. En estas condiciones, el dispositivo de extinción fue insuficiente ya que por cada incendio que se controlaba o extinguía surgían varios nuevos incendios en otros puntos. La situación llevó a la Xunta de Galicia a solicitar ayuda extraordinaria, el día 6 de agosto, no sólo del Ministerio de Medio Ambiente, sino también de otros departamentos ministeriales (Ministerio de Interior y Ministerio de Defensa), de otras Comunidades Autónomas y hasta de otros países. La situación comenzó a mejorar el 10 de agosto y finalizó con la llegada de un frente atlántico el día 15 de agosto que aportó precipitaciones en todo el noroeste peninsular (ADCIF, 2006).

Este artículo pretende mostrar un ejemplo práctico de cómo la teledetección puede usarse para facilitar información relevante en situaciones de gestión de crisis ambientales. Presenta los procesos realizados para abordar una cartografía y evaluación de las áreas quemadas en Galicia durante el episodio de incendios antes comentado. El trabajo se enmarca en el proyecto europeo PREVIEW (Prevention, Information and Early Warning), que forma parte del programa Europeo GMES (Global Monitoring for Environment and Security - http://www.gmes.info/), y está centrado en el análisis de riesgos naturales a partir de teledetección. Una parte de este proyecto aborda el desarrollo de productos operativos a partir de imágenes de satélite que faciliten información crítica sobre los impactos del fuego en el territorio (Valcarce et al., 2007). El trabajo que aquí se presenta aborda la cartografía y evaluación de las zonas afectadas en tiempo casi real, a partir del uso de imágenes adquiridas por los sensores MODIS a bordo de los satélites TERRA y AQUA el 13 y 21 de agosto de 2006. Una delimitación más precisa de los incendios se realizó a partir de una imagen de mayor resolución espacial adquirida por el sensor AWiFS (Advanced Wide Field Sensor), a bordo del satélite indio IRS-P6.

La cartografía obtenida permitió realizar un análisis territorial de las zonas afectadas al cruzarla con información cartográfica sobre determinadas características del territorio (límites administrativos, ocupación del suelo, altitudes, etc.). Por último, se realizó una evaluación de la severidad de los incendios mediante la comparación temporal entre imágenes MODIS previas y posteriores a los incendios, empleando para ello los cambios en un índice espectral de área quemada denominado BAI (Burned Area Index) (Martín, 1998). En la mayoría de los casos, la severidad del incendio es un parámetro que no se incluye en los partes de incendio, ya que el trabajo de campo que requiere es costoso. Por ello, consideramos que este análisis ofrecería un valor añadido en la planificación de medidas de recuperación de las zonas afectadas ya que la información sobre los niveles de severidad resulta un elemento clave para prever la evolución ecoló- 
gica de las áreas afectadas y los efectos a medio y largo plazo que el incendio supone sobre el ecosistema.

Toda la información generada fue facilitada a los responsables de la gestión, a escala regional y nacional, y difundida a través de una página web que incluye un servidor cartográfico (http://www.geogra.uah.es/galicia/evaluacion-severidad.php) diseñado para facilitar el acceso a la información cartográfica generada así como a la descripción de la metodología utilizada.

\section{Material y métodos}

\subsection{Cartografía de áreas quemadas con imágenes MODIS y AWiFS}

Para obtener una evaluación rápida y una primera cartografía de las áreas afectadas, se utilizaron imágenes procedentes del sensor MODIS a bordo de la plataforma AQUA. Este sensor ofrece una resolución espacial y temporal adecuada para la cartografía de áreas quemadas a escala regional (Martín et al., 2002; Roy et al., 2005b; Roy et al., 2002). Por otra parte las imágenes están disponibles de forma gratuita y casi inmediata a su adquisición a través de servidor de la NASA en la dirección: http://edcimswww.cr.usgs.gov/ims-bin/pub/nph-ims.cgi. Para este estudio se utilizaron los productos MYD09GHK (http://edcdaac.usgs.gov/modis/myd09ghkv4.asp) y MYD09GQK (http:// edcdaac.usgs.gov/modis/myd09gqkv4.asp) adquiridos por el satélite AQUA-MODIS el 13 de agosto de 2006 a las 13:50 UTC sobre la Península Ibérica (Tabla 1). El primero incluye datos de reflectividad en 7 bandas espectrales que van del visible al infrarrojo medio de onda corta con una resolución espacial de $500 \mathrm{~m}$. El producto MYD09GQK incluye sólo dos bandas espectrales (rojo e infrarrojo cercano) pero presenta mejor resolución espacial (250 m.).

Tabla 1. Principales características de las imágenes MODIS

\begin{tabular}{|l|c|c|c|}
\hline Producto & Banda & Longitud de onda $(\mathrm{nm})$ & Tamaño del Píxel $(\mathrm{m})$ \\
\hline MYD09GQK & 1 & $620-670$ & 250 \\
& 2 & $841-876$ & 500 \\
\hline MYD09GHK & 1 & $620-670$ & \\
& 2 & $841-876$ & \\
& 3 & $459-479$ & \\
& 4 & $545-565$ & \\
& 5 & $1230-1250$ & \\
& 6 & $1628-1652$ & \\
& 7 & $2105-2155$ & \\
\hline
\end{tabular}

Fuente: Adaptado de http://ltpwww.gscf.nasa.gov/MODIS/MODIS.html 
Las imágenes originales se encuentran en proyección Sinusoidal por lo que fueron reproyectadas a UTM utilizando como referencia el Elipsoide Europeo de 1950 con el propósito de hacer los resultados compatibles con la cartografía oficial.

Los perímetros de las zonas quemadas se obtuvieron mediante digitalización en pantalla utilizando como referencia para la identificación visual de las zonas afectadas una composición en falso color RGB (bandas 2/1/1) de la imagen MODIS de 250 metros por ser la que ofrece mayor detalle espacial. Para confirmar visualmente las áreas quemadas nos apoyamos en la visualización simultánea de una composición en falso color utilizando las bandas 7/2/1 (infrarrojo medio, cercano y rojo) de la imagen de $500 \mathrm{~m}$. Además, y para evitar posibles confusiones con otras superficies que pudieran ofrecer un comportamiento espectral similar al de las zonas quemadas, como por ejemplo las láminas de agua, utilizamos como referencia una imagen MODIS previa a los incendios adquirida en el verano de 2005 que nos permitía confirmar, antes de proceder a la digitalización del polígono, si se había producido un cambio en la respuesta espectral entre las dos fechas que pudiera deberse al incendio. El empleo del análisis visual para delimitar áreas quemadas ha sido propuesto por diversos autores (Roy et al., 2005a), y resulta una estrategia bastante segura de delimitación, gracias al marcado contraste del área quemada con su contexto.

La evaluación de áreas quemadas realizada a partir de imágenes AQUA-MODIS adquiridas el 13 de agosto de 2006 fue actualizada a partir de imágenes TERRA-MODIS (con las mismas características espectrales y espaciales ya citadas) adquiridas el 21 de agosto de 2006 (productos MOD09GQK y MOD09GHK). Como se mencionó en la introducción, la llegada del frente atlántico el 15 de agosto facilitó la extinción de la mayor parte de los incendios ese día, pero algunos permanecieron activos durante algunas horas lo que hizo que se modificase el perímetro final respecto al observado en la imagen del día 13. En el intervalo de tiempo transcurrido entre la adquisición de las dos imágenes también se produjeron nuevos incendios que pudieron ser incorporados a la cartografía final.

Como ya hemos mencionado, las imágenes MODIS resultan especialmente adecuadas para la evaluación rápida de fenómenos, como el de los incendios forestales a una escala regional. La alta resolución temporal de este sensor y su disponibilidad casi inmediata y gratuita a través del servidor de la NASA (Justice et al., 2002), permitieron disponer de una primera evaluación de daños tan sólo 5 días después de la adquisición de la imagen. Una evaluación más detallada fue posible 4 semanas después mediante el uso de imágenes de mayor resolución espacial. Concretamente se utilizó una imagen del sensor AWiFS a bordo del satélite ResourceSat-1 (IRS-P6) adquirida el 21 de agosto de 2006 a las 11:05 sobre la Península Ibérica. Este sensor recoge información en cuatro bandas espectrales (verde, rojo, infrarrojo cercano e infrarrojo medio de onda corta) y posee una resolución espacial de 60 metros (Seshadri et al., 2005).

En el caso de la imagen AWiFS se aplicaron diversos procesos previos a la interpretación como la corrección geométrica de la imagen y la conversión a reflectividades. 
Las imágenes se convirtieron a proyección UTM, utilizando como referencia el Elipsoide Europeo de 1950, al igual que las imágenes MODIS.

Los perímetros se digitalizaron en pantalla mediante la interpretación visual de una composición en color utilizando las bandas 4/3/2 (SWIR, IRC, R), en la que los incendios son claramente visibles en tonos magenta.

Los polígonos generados a partir de las imágenes MODIS y AWiFS se exportaron al formato Shape de ArcView y se incorporaron al servidor cartográfico que permite su visualización interactiva combinada con otras capas de información (vegetación, cartografía base, imágenes de satélite, etc.), así como la comparación visual de la cartografía obtenida con ambos sensores.

\subsection{Estimación de la severidad de los incendios con imágenes MODIS}

El análisis del impacto causado por los incendios sobre la vegetación y los suelos es una parte clave de su evaluación, de cara a paliar sus efectos negativos. En este marco, la delimitación de niveles de severidad resulta especialmente interesante (Key y Benson, 2005). La mayor parte de los estudios sobre severidad post-incendio se han basado en trabajo de campo (Pérez Moreno, 1998), pero en los últimos años se han propuesto algunas técnicas para estimar esa variable a partir de imágenes de satélite (de Santis y Chuvieco, 2007; Lentile et al., 2006).

Para este trabajo, la evaluación de la severidad de los incendios se realizó a partir del análisis multitemporal de imágenes AQUA-MODIS adquiridas el 14 de agosto de 2005 (un año anterior a los incendios) y el 13 de agosto de 2006 (posterior a la mayor parte de los incendios). Se utilizó el producto MYD09GHK de MODIS antes comentado. El análisis de la severidad se limitó a las áreas identificadas como quemadas a partir de la interpretación visual de imágenes MODIS de 250 m. adquiridas el 13 de agosto.

La estimación de la severidad se basó en el análisis multitemporal de un índice espectral diseñado específicamente para la cartografía de área quemada y denominado BAI (Burned Area Index). Este índice, propuesto por Martín (1998) para imágenes NOAA-AVHRR, intenta medir la similitud espectral entre cada píxel de la imagen y un punto de convergencia, hacia el que tendería una zona plenamente quemada, donde domine la señal del carbón. Su utilización se ha ensayado en diversos sensores con buenos resultados (Chuvieco et al., 2002). Recientemente se adaptó a las características del sensor MODIS (Martín et al., 2005), calculándose en este caso como:

$$
B A I M=\frac{1}{\left(p c_{I R C}-\rho_{I R C}\right)^{2}+\left(p c_{\text {SWIR }}-\rho_{\text {SWIR }}\right)^{2}}
$$

donde $\rho_{\text {irc }}=$ banda 2 , que corresponde al infrarrojo cercano, y $\rho_{\text {swir }}=$ banda 7 , que corresponde al infrarrojo medio de onda corta (en torno a 2 micras). Los valores de $\mathrm{pc}_{\mathrm{irc}}=0,08$ $\mathrm{y} \mathrm{pc}_{\mathrm{swir}}=0,2$, indican el punto de convergencia. 
Consideramos que el cambio en el valor de este índice entre las imágenes previa y posterior al fuego era un buen indicador de la transformación producida por el incendio, especialmente del cambio de la señal vegetal a la de carbón. Desde el punto de vista de la modelización teórica, esta asunción puede considerarse bastante razonable (Chuvieco et al., 2006). A partir de la imagen de cambios en el BAIM se han establecido tres rangos de severidad, en función del histograma de esa imagen, codificándose como rangos de severidad baja, media y alta.

También hemos aplicado otro índice espectral comúnmente aplicado a la determinación de la severidad de quemado. Se denomina NBR (Normalized Burned Area), y fue propuesto en el marco de un proyecto del servicio forestal de EE.UU. para evaluar áreas quemadas a partir de teledetección (proyecto Firemon, Key y Benson, 2005), si bien se había propuesto unos años antes por López y Caselles (1991). El NBR se formula de la siguiente forma:

$$
N B R=\frac{\rho_{\text {swir }-} \rho_{i r c}}{\rho_{\text {swir }+} \rho_{i r c}}
$$

donde SWIR e IRC tienen el mismo significado que en la fórmula (1). Al igual que hicimos con el BAIM, también se utilizó el cambio temporal del NBR para estimar la severidad de las áreas quemadas. También en este caso, se señalaron tres niveles de severidad en función de los valores del histograma de la imagen de cambios.

De cara a obtener una evaluación final de la severidad, transformamos las clases de severidad baja, media y alta obtenidas de los índices anteriores a una escala conjunta de severidad. Para ello, empleamos el índice CBI (Composite Burned Index), que ha sido recientemente propuesto en el marco del proyecto Firemon (http://www.fire.org/, Key y Benson, 2005). El CBI varía de 0 (no quemado) a 3 (máxima severidad), considerando el cambio experimentado en la zona quemada en distintos estratos de la vegetación (cambio en el color del suelo, en la hoja, en la cantidad de hojas, altura del carbón, etc.). La conversión se realizó a partir de las ecuaciones que relacionan el valor del CBI con el NBR post-incendio, basadas en las simulaciones antes comentadas (Chuvieco et al., 2006). Las ecuaciones permiten estimar un valor de severidad para cada una de las clases generadas previamente. A partir de los píxeles incluidos en cada una de esas tres clases, se han calculado los rangos de valores CBI de los niveles de severidad bajos, medios y altos en la imagen del NBR y del BAI post-incendio y se ha obtenido un promedio entre ellos para calcular el valor de severidad final:

$$
S e v=\frac{\left(S e v_{N B R}+S e v_{B A I M}\right)}{2}
$$

\subsection{Análisis territorial de los daños}

Una vez generada la cartografía de los incendios, los perímetros se cruzaron con información cartográfica sobre determinadas características del territorio (límites admi- 
nistrativos, ocupación del suelo, altitudes, etc.). Se realizaron diversos análisis espaciales con objeto de obtener una primera evaluación y una referencia rápida para valorar el impacto causado por los recientes incendios en esa Comunidad Autónoma.

La información geográfica analizada para este análisis territorial de los daños fue:

- Provincias y términos municipales: Base cartográfica del Instituto Geográfico Nacional a escala 1:200.000.

- Tipos de vegetación, Mapa Forestal de España, 1:200.000, Dirección General para la Biodiversidad, Ministerio de Medio Ambiente.

- Áreas protegidas, escala 1:200.000, Dirección General para la Biodiversidad, Ministerio de Medio Ambiente.

- Tipos de cobertura: Mapa CORINE-Land Cover 2000, coordinado por el Instituto Geográfico Nacional para la Agencia Europea de Medio Ambiente, escala original 1:100.000.

- Pendiente y altitudes: Modelo digital de elevaciones extraído del mapa topográfico nacional a escala 1:25.000.

- Inventario Nacional de Estados Erosivos, Ministerio de Medio Ambiente, a escala 1:200.000.

Las bases de datos de referencia fueron facilitadas por la Dirección General para la Biodiversidad (DGB) en el marco del convenio suscrito entre la Universidad de Alcalá y el Ministerio de Medio Ambiente para la elaboración y el suministro de información relevante a efectos de la planificación de medios en la lucha contra los incendios forestales en la Península y en las Islas Baleares.

Puesto que los incendios de Galicia habían tenido un gran impacto en la opinión pública, pareció conveniente hacer disponible esta información de la manera más abierta posible. Para ello, generamos un servidor cartográfico en Internet, aprovechando la experiencia previa de nuestro grupo en proyectos de riesgo de incendio. Este servidor incluía información sobre perímetros quemados, niveles de daño y evaluación de zonas afectadas (http:// www.geogra.uah.es/galicia/evaluacion-severidad.php).

\section{Resultados}

\subsection{Cartografía de áreas quemadas con imágenes MODIS y AWiFS}

El análisis visual de las imágenes MODIS permitió generar la cartografía de las áreas quemadas hasta el día 13 de agosto y 21 de agosto (Figura 1). Dada la resolución espacial de las imágenes utilizadas las áreas quemadas visibles en la imagen normalmente superan las 50 ha, aunque en algunos casos se han cartografiado también áreas con superficies comprendidas entre las 25 y las 50 ha, que corresponden con incendios donde el contraste espectral entre la zona afectada y las cubiertas vecinas es muy grande, lo que puede ser debido al tipo y características de la vegetación afectada, el nivel de severidad, etc. 
Con las limitaciones propias de la resolución espacial de las imágenes utilizadas, la superficie total quemada en Galicia hasta el día 13 de agosto estimada con el procedimiento descrito a partir de imágenes MODIS alcanza las 92.058 ha. (Tabla 2).

La actualización realizada mediante el análisis de las imágenes MODIS del 21 de agosto, nos permitió mejorar y ajustar los perímetros de algunos incendios que estaban aún activos durante el día 13. Se trata de dos grandes incendios (con superficie superior a las 1.000 ha.), el primero afectó al municipio de Negreira en La Coruña y el segundo a los municipios de A Lama en Pontevedra y Avión en Orense. En estos casos los nuevos perímetros sustituyen a los anteriores que estaban incompletos y presentaban algunos errores de delimitación ocasionados por las plumas de humo procedentes de los incendios activos y que contaminaban parcialmente las imágenes del día 13. Se delimitaron además, a partir de la imagen del día 21, otros tres nuevos perímetros que corresponden a incendios inferiores a 100 ha., dos de ellos en La Coruña y el último en Orense. La nueva superficie total estimada a fecha 21 de agosto asciende a 92.749 ha.
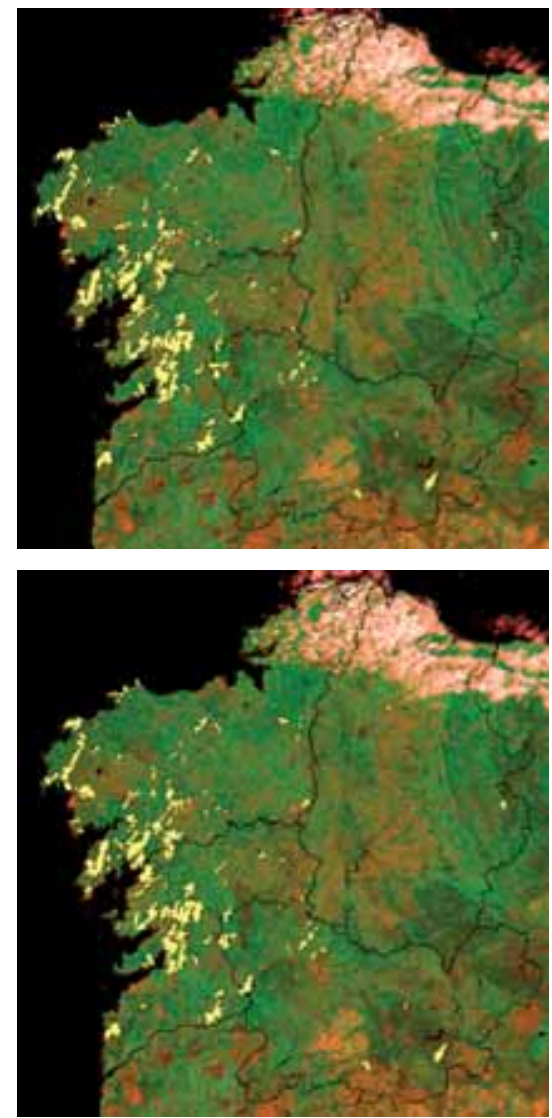

Figura 1. Cartografía de incendios a partir de imágenes MODIS del 13 de agosto (arriba) y 21 de agosto (abajo) 
Por lo que respecta a la cartografía obtenida a partir de la imagen AWiFS, la mayor resolución espacial de esta imagen $(60 \mathrm{~m}$. frente a $250 \mathrm{~m}$.) ha permitido cartografiar incendios superiores a 1 ha, e incluso algunos menores. Los resultados obtenidos arrojan un total de 103.726 hectáreas ardidas (Tabla 2).

Tabla 2. Superficie quemada estimada con MODIS (13 agosto) y AWiFS

\begin{tabular}{|l|c|c|}
\hline Provincia & MODIS (ha) & AWiFS (ha) \\
\hline La Coruña & 42.983 & 46.481 \\
\hline Lugo & 1.057 & 2.045 \\
\hline Orense & 7.308 & 11.827 \\
\hline Pontevedra & 40.710 & 43.373 \\
\hline TOTAL & 92.058 & 103.726 \\
\hline
\end{tabular}

\subsection{Estimación de la severidad de los incendios con imágenes MODIS}

Las clases resultantes del análisis de severidad pueden catalogarse de la forma siguiente:

- Severidad moderada $(1,5<\mathrm{CBI}<2,25)$. Corresponde a zonas que han consumido la mayor parte del combustible del suelo y del estrato de matorral, con porcentajes de quemado por encima del $60 \%$ y escasa presencia de plantas verdes. En el estrato superior (árboles por encima de 5 metros) pueden existir copas poco dañadas, con cambio de follaje inferior al $60 \%$ y abundancia de hojas.

- Severidad moderada-alta $(2,25<\mathrm{CBI}<2,75)$. Corresponde a zonas donde el estrato inferior se ha consumido casi completamente, tanto suelo como matorral y árboles bajos, y quedan copas con alteración moderada, entre el 60 y el $90 \%$ del follaje.

- Severidad alta $(2,75<\mathrm{CBI}<3,00)$. Tanto el estrato inferior como el superior han sido prácticamente eliminados, con un porcentaje de hojas verdes menor al 10\%, dominio de hojas quemadas o chamuscadas (>90\%) y altura del carbón en los árboles por encima de $4 \mathrm{~m}$.

Esta descripción corresponde a los valores promedio de las variables inventariadas en el CBI. Para el caso gallego, convendría verificar el ajuste a las condiciones de las cubiertas vegetales afectadas. 


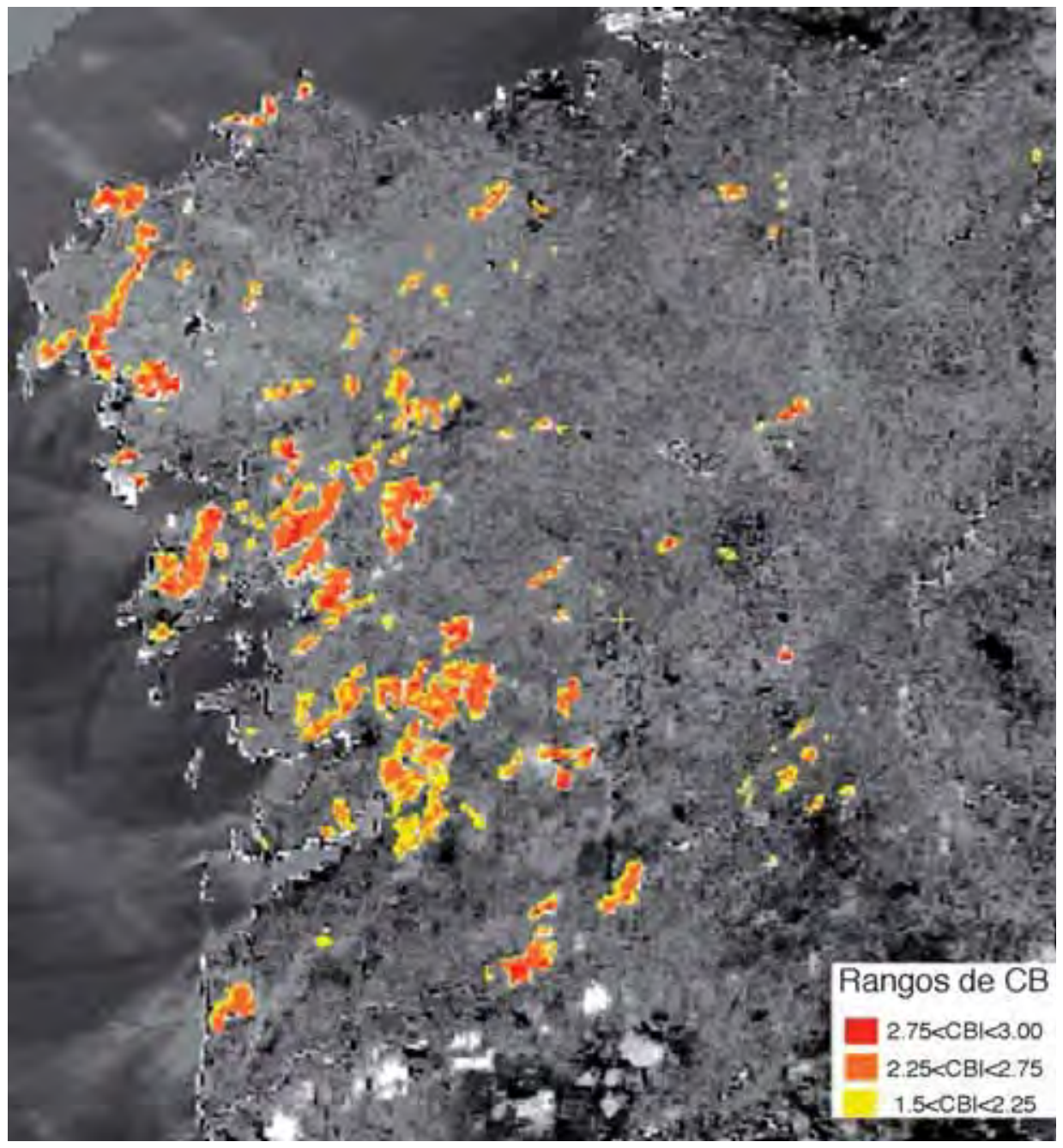

Figura 2. Clases de severidad estimadas a partir del cambio temporal del BAI y del NBR

La superficie global catalogada como de alta severidad supera las 8.000 ha., mientras la de severidad moderada-alta alcanza las 50.000 ha. El resto (más de 33.000 ha.) puede considerarse como severidad moderada. Los valores no difieren mucho de la evaluación realizada con los dos índices por separado, por lo que hemos considerado exclusivamente el cruce entre ellos.

\subsection{Análisis territorial de los daños}

Se presentan una serie de gráficos y comentarios que permiten una primera evaluación del impacto causado por los incendios forestales en Galicia hasta el 13 de agos- 
to de 2006, sobre la base cartográfica citada previamente. Este primer análisis demuestra la capacidad combinada de los SIG y la teledetección para ofrecer una estimación rápida que permita valorar el impacto causado por los incendios. El análisis se realizó sobre la cartografía realizada a partir de la imagen MODIS del día 13 para proporcionar una primera evaluación en el menor tiempo posible.

La importancia de las superficies quemadas resulta obvia a la vista de los valores absolutos y relativos de superficies afectadas por el fuego. De acuerdo a las áreas determinadas como quemadas en las imágenes AQUA-MODIS, hasta el 13 de agosto de 2006 se habían incendiado en Galicia algo más de 92.000 ha, lo que suponía el 3,1\% de la superficie regional y el 4,7\% de la superficie catalogada como forestal (que incluye arbolado, matorral y pastos). En la imagen se han discriminado un total de 120 áreas quemadas, que presentan una distribución de superficies bastante homogénea (Tabla 3). La mayor parte de la superficie quemada corresponde a incendios grandes, destacando 24 con más de 1.000 ha. Es preciso recordar que la delimitación de los incendios pequeños (por debajo de 50 hectáreas) es menos fiable debido a la resolución espacial de las imágenes utilizadas.

Tabla 3. Incendios forestales según tamaño de la superficie quemada

\begin{tabular}{|c|c|}
\hline Superficie quemada (ha) & $\mathrm{N}^{\mathrm{o}}$ de incendios \\
\hline$<50$ & 16 \\
$51-100$ & 13 \\
$101-150$ & 10 \\
$151-200$ & 15 \\
$201-250$ & 9 \\
$251-500$ & 18 \\
$501-1000$ & 15 \\
$>1000$ & 24 \\
Total & 120 \\
\hline
\end{tabular}

Al relacionar la cartografía de áreas quemadas con los límites administrativos a escala provincial y municipal observamos que las áreas más intensamente quemadas corresponden a las provincias del litoral, Coruña y Pontevedra, que superan el $90 \%$ de toda la superficie afectada por los incendios. En estas provincias es donde se ha quemado el porcentaje más significativo del total provincial, 5,38\% en Coruña y 9,02\% en Pontevedra. Entre los municipios más afectados, destaca el impacto relativo de los incendios en los municipios de Campo Lameiro, Soutomaior, y Pontecesures en Pontevedra; y los de Padrón y Rianxo en Coruña, en donde se quemó más del $40 \%$ de la superficie municipal. 
Para analizar las principales clases de cobertura del suelo afectadas por los incendios se utilizó el Corine-Land Cover 2000. Conviene recordar que éste no es propiamente un mapa de especies vegetales, sino más bien de formaciones biogeográficas que explican la ocupación actual del suelo. El inventario con el que se han cruzado los perímetros quemados se realizó entre 2000 y 2005, con imágenes adquiridas en el 2000 o años vecinos cuando hubiera alta cobertura de nubes (http://image2000.jrc.it/clc/index.cfm).

Entre los tipos de ocupación más afectados por el fuego destaca el bosque mixto, que supone la cobertura más intensamente quemada, por encima de las 35.000 ha. Se trata de formaciones donde se mezcla el bosque caducifolio y el perennifolio. El matorral boscoso de transición también tiene un papel protagonista, con algo más de 22.000 ha., seguido de los pastizales, principalmente templado oceánicos, muy abundantes en Galicia y asociados a su amplia vocación ganadera. Aunque en números absolutos resulte menos relevante, conviene destacar por su importancia social las 284 ha. quemadas en zonas definidas como urbanas, ya sea en los márgenes de núcleos consolidados, en infraestructuras o en urbanizaciones de reciente creación. También interesa remarcar la importante cantidad de áreas agrícolas afectadas por el fuego, tanto en mosaicos de cultivos, como en mosaicos de cultivo y vegetación natural, lo que indica una propagación importante en las interfases agrícola-forestales.

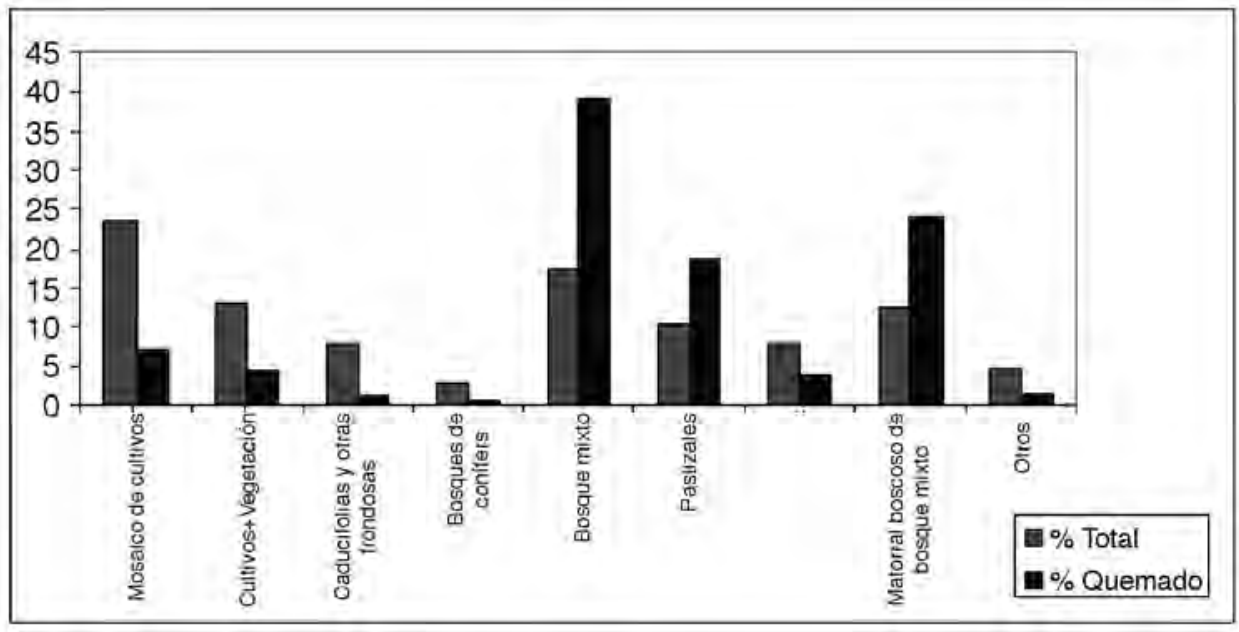

Figura 3. Proporción de los tipos de cobertura afectados por los incendios

Además de analizar los datos globales, también conviene detenerse en la proporción de las distintas cubiertas afectadas por el fuego respecto al total que ocupan en la superficie regional (Figura 3). Destaca, en este sentido, el mayor impacto de algunos tipos de cobertura, como el bosque mixto, que se ha quemado en una proporción doble a la que ocupa en la Comunidad Autónoma, así como el pastizal y el matorral boscoso. Por el contrario, los mosaicos de cultivos y las caducifolias se han quemado en proporción significativamente menor a la que ocupan en el total regional. 
El mapa forestal de España permite enriquecer algunos de estos comentarios sobre los tipos de vegetación afectados por el fuego. La proporción más importante del área quemada corresponde a bosques de alto porte ( $>7 \mathrm{~m}$.), con casi un $30 \%$ del total afectado. Las repoblaciones forestales (principalmente de eucalipto) suponen casi un $25 \%$ del total, mientras los matorrales medios y altos acogen casi otro $25 \%$. No puede concluirse, por tanto, que las especies exóticas hayan sido las más afectadas por los incendios.

Por lo que respecta a la topografía, como es sabido, juega un papel determinante en el inicio y la propagación del fuego, por su efecto directo en la temperatura y humedad relativa del aire (gradientes térmicos, efectos de exposición), así como en la propagación del frente de llamas. A partir de los perímetros quemados, podemos señalar los rangos altitudinales y de pendiente más afectados por el fuego (Figura 4).

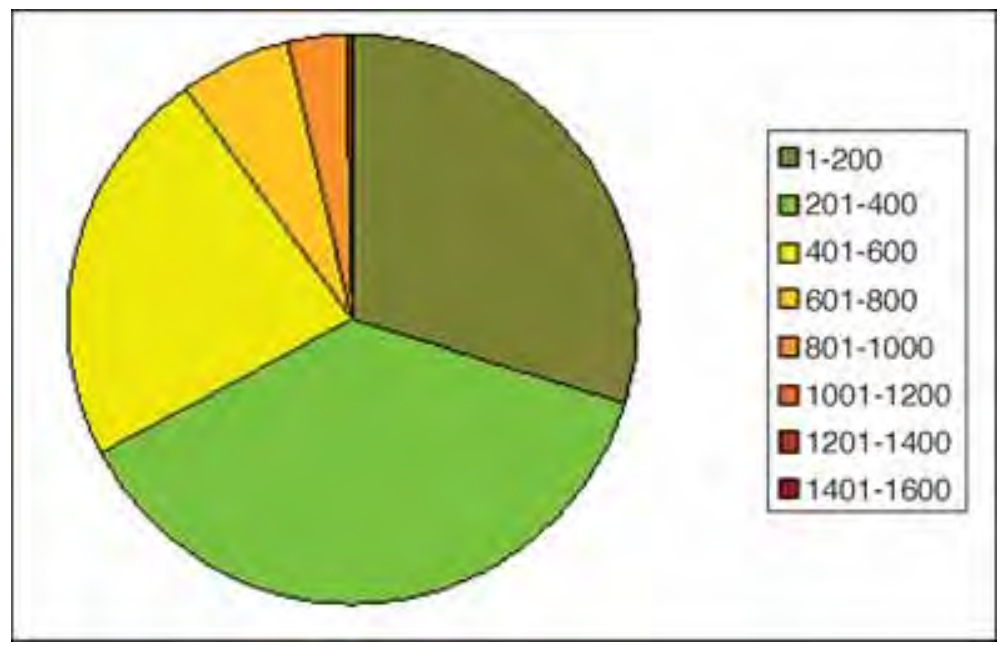

Figura 4. Rangos de altitud afectados por los incendios (en m.)

La mayor parte de los sectores quemados están por debajo de los $600 \mathrm{~m}$. de altitud (casi el 90\%). Como hemos indicado antes, las zonas más afectadas están cerca del litoral, lo que también explica que sean dominantes los rangos más bajos de altitudes.

La distribución de las áreas quemadas en rangos de pendientes muestra una distribución mucho más uniforme, cubriendo casi todos los rangos considerados. Esto supone que la propagación ha sido muy variada, tanto en sectores rugosos como en otros de menor declive. Es interesante destacar que por encima del $20 \%$ de pendiente se encuentra una parte muy significativa del área quemada (superior al 45\%), lo que supone un riesgo añadido en relación con el potencial erosivo y es un dato relevante de cara a la gestión post-incendio de las zonas afectadas. 


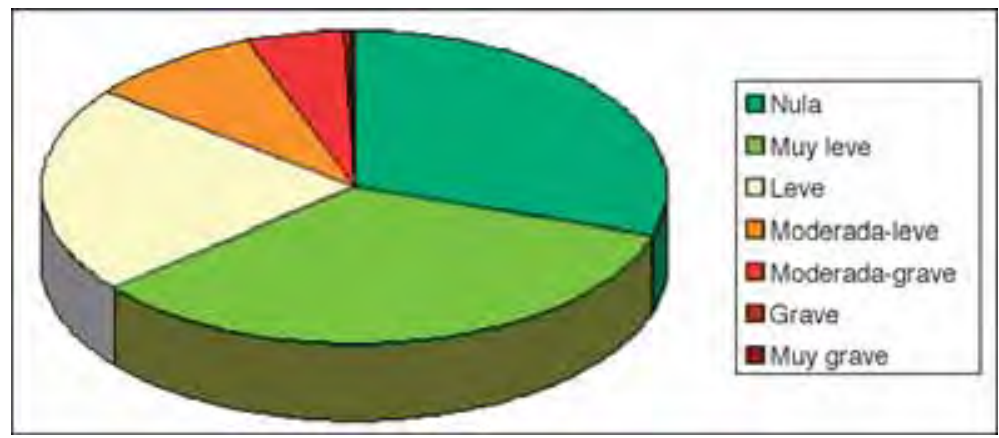

Figura 5. Estados erosivos en las áreas afectadas por los incendios

Otro dato de gran interés en el análisis territorial de la evaluación de daños se refiere al nivel de afectación de las zonas naturales protegidas. En términos absolutos, las áreas naturales más afectadas han sido la Sierra de los Ancares, Carnota-Monte Pindo, la Costa da Morte y la Serra do Careón, que albergan casi el $80 \%$ de todo lo quemado en espacios protegidos. No obstante, conviene también considerar la proporción quemada de cada uno de los espacios, y ahí los casos más graves son el Río Lérez, con algo más del $35 \%$ de su superficie quemada, y las Brañas de Xestoso, con algo más del 17\%.

Por último, el cruce del mapa de estados erosivos facilitado por el Ministerio de Medio Ambiente con las superficies quemadas nos indica que, afortunadamente, la mayor parte de la superficie quemada estaba catalogada como de peligro leve o moderado de erosión (Figura 5), lo que permitiría centrar los esfuerzos de recuperación en los sectores más frágiles. A partir de una cartografía más precisa, tanto de los perímetros quemados como de las variables de control más importantes (erosividad de la lluvia, protección del manto vegetal, pendientes, etc.), se podría realizar una evaluación más refinada de esta variable, que resulta clave en la evolución post-incendio de las áreas afectadas por los fuegos.

\section{Discusión y conclusiones}

El uso de imágenes de satélite y sistemas de información geográfica resulta de indudable utilidad en la gestión de riesgos naturales y antrópicos. En esta línea se sitúa la investigación que viene desarrollando el grupo de Tecnologías de la Información Geográfica del IEG-CSIC en colaboración con el grupo de Teledetección ambiental del Departamento de Geografía de la Universidad de Alcalá (UA) en el marco de la Unidad Asociada GEOLAB.

Resulta evidente el interés de la teledetección espacial en este contexto, ya que facilita imágenes sobre el conjunto del territorio (exhaustivas espacialmente) y a intervalos regulares (adquiridas sistemáticamente). La disponibilidad actual de imágenes con diversa resolución espectral, espacial y temporal permite además abordar estudios a 
diversas escalas para obtener una evaluación rápida a la vez que precisa de los efectos de los incendios.

A raíz de los incendios forestales que afectaron a Galicia durante agosto de 2006 y en el marco del proyecto Europeo PREVIEW, cuyo objetivo general es la definición, el desarrollo y la validación de los servicios de información en condiciones pre-operacionales para apoyar la gestión de catástrofes, entre las que se incluyen los incendios forestales (Valcarce et al., 2007), se realizó una primera evaluación de los efectos de los incendios en Galicia. El primer objetivo de esta evaluación fue la delimitación de los perímetros de las áreas afectadas a partir de imágenes procedentes del sensor MODIS, a bordo de las plataformas TERRA y AQUA. Una primera cartografía de las áreas quemadas se realizó a partir de imágenes MODIS adquiridas el día 13 de agosto. Teniendo en cuenta que en esa fecha algunos grandes incendios continuaban activos, la delimitación de los perímetros fue actualizada con imágenes del día 21 de agosto. El método utilizado en este análisis, la interpretación visual de imágenes pre y post-incendio, es el que permite obtener una estimación aproximada de carácter global más rápida. La precisión de la estimación está, por supuesto, condicionada por la resolución espacial de las imágenes utilizadas que pueden presentar una tendencia a la sobreestimación, especialmente en las áreas de borde donde puede contabilizarse como quemada la superficie total del píxel (250 m.) aunque sólo una parte haya sido realmente afectada por el fuego. No obstante esta posible sobreestimación puede verse compensada por la infraestimación que se produce al no ser posible detectar los incendios de menores dimensiones (especialmente aquellos que afectaron a una superficie total inferior a 50 ha.). A pesar de las limitaciones pensamos que la información ha resultado de gran interés para obtener una primera evaluación global de los efectos de los incendios en la región.

La estimación realizada con AWiFS ha mejorado la obtenida con MODIS, ya que la sobreestimación debida a las áreas de borde queda reducida, si bien en los incendios pequeños todavía se puede registrar cierta sobreestimación. Por otro lado, se ha logrado identificar incendios a partir de 1 ha., de manera que también se reduce la infraestimación originada por la resolución espacial del sensor MODIS.

Se ha realizado una evaluación preliminar de la severidad de los incendios empleando imágenes de resolución media AQUA-MODIS. La estimación de niveles de severidad se ha realizado a partir del cambio observado en dos índices espectrales bien conocidos en este tipo de análisis. La ausencia de bandas en el infrarrojo de onda corta (SWIR) ha impedido realizar esta evaluación con las mismas imágenes (producto MYD09GQK de 250 m.) que se emplearon en la delimitación de los incendios.

En nuestra opinión, el mayor interés de esta evaluación es determinar rápidamente las zonas con mayor vulnerabilidad potencial post-incendio, priorizando las tareas de defensa y recuperación. El cruce de esta estimación de la severidad, con los mapas de vegetación, estados erosivos y pendientes, permitiría obtener una estimación más precisa del potencial de erosión y capacidad de regeneración de las cubiertas. 
Una vez generada la cartografía de los incendios, los perímetros se han cruzado con información cartográfica sobre determinadas características del territorio (límites administrativos, ocupación del suelo, altitudes, etc.). Sin ánimo de entrar en valoraciones que no nos competen, se presentan los resultados preliminares de una evaluación territorial de las zonas afectadas por el fuego, que esperamos sirva para mejorar nuestro conocimiento del fenómeno y contribuya a paliar sus efectos negativos sobre el medioambiente y la sociedad gallega.

Finalmente, una fase de gran relevancia en este estudio fue la difusión de la información generada a través de una página web y un servidor cartográfico. Esta herramienta facilitó la difusión de la información en tiempo "casi real" tanto a los responsables de la gestión a escala nacional y regional, como a otros investigadores y al público en general.

\section{Agradecimientos}

Los autores desean expresar su agradecimiento a la NASA por facilitar de forma gratuita las imágenes MODIS utilizadas en este estudio a través de su servidor EOS Data Gateway (http://edcimswww.cr.usgs.gov/ims-bin/pub/nph-ims.cgi).

\section{Referencias bibliográficas}

ADCIF (2006). Incendios Forestales en España. Año 2006: Avance informativo. Dirección General para la Biodiversidad, Ministerio de Medio Ambiente, Madrid.

Arino, O., Piccolini, I., Kasischke, E., Siegert, F., Chuvieco, E., Martín, P., Li, Z., Fraser, H., Eva, H., Stroppiana, D., Pereira, J., Silva, J.M.N., Roy, D. y BarBOSA, P. (2001). Methods of mapping burned surfaces in vegetation fires. En Global and Regional Vegetation Fire Monitoring from Space: Planning a coordinated international effort (Ahern, Goldammer y Justice, Ed.). SPB Academic Publishing, The Haghe, The Netherlands, 227-255.

Chuvieco, E., Martín, M.P. y Palacios, A. (2002). Assessment of different spectral indices in the red-near-infrared spectral domain for burned land discrimination. International Journal of Remote Sensing 23: 5103-5110.

Chuvieco, E., Riaño, D., Danson, F.M. y Martín, M.P. (2006). Use of a radiative transfer model to simulate the post-fire spectral response to burn severity. Journal of Geophysical Research - Biosciences 111 G04S09, doi:10.1029/2005JG000143.

De Santis, A. y Chuvieco, E. (2007). Burn severity estimation from remotely sensed data: Performance of simulation versus empirical models. Remote Sensing of Environment 108: 422-435. 
Justice, C.O., Townshend, J.R.G., Vermote, E.F., Masuoka, E., Wolfe, R.E., Saleous, N., Roy, D.P. y MorisetTe, J.T. (2002). An overview of MODIS Land data processing and product status. Remote Sensing of Environment 83: 3-15.

Key, C.H. y Benson, N. (2005). Landscape Assessment: Ground measure of severity, the Composite Burn Index; and Remote sensing of severity, the Normalized Burn Ratio. En FIREMON: Fire Effects Monitoring and Inventory System, Vol. 2004. Lutes, Keane, Caratti, Key, Benson y Gangi. USDA Forest Service, Rocky Mountain Research Station, Gen. Tech. Rep. RMRS-GTR-164, Ogden, UT: pp. CD: LA1-LA51.

LeE, B., PARK, P.S. y Chung, J. (2006). Temporal and spatial characteristics of forest fires in South Korea between 1970 and 2003. International Journal of Wildland fire 15: 389-396.

Lentile, L.B., Holden, Z.A., Smith, A.M.S. y FALKowski, M.J., et al. (2006). Remote sensing techniques to assess active fire characteristics and post-fire effects. International Journal of Wildland fire 15: 319-345.

López García, M.J. y CAselles, V. (1991). Mapping Burns and Natural Reforestation Using Thematic Mapper Data. Geocarto International 1: 31-37.

Martín, M.P. (1998). Cartografía e inventario de incendios forestales en la Península Ibérica a partir de imágenes NOAA-AVHRR. Departamento de Geografía. Tesis Doctoral. Departamento de Geografía. Universidad de Alcalá, Alcalá de Henares.

Martín, M.P., Díaz-Delgado, R., Chuvieco, E. y Ventura, G. (2002). Burned land mapping using NOAA-AVHRR and TERRA-MODIS. En IV International Conference on Forest Fire Research. 2002 Wildland Fire Safety Summit. Millpress, Luso, Coimbra, Portugal.

Martín, M.P., Gómez, I. y Chuvieco, E. (2005). Performance of a burned-area index (BAIM) for mapping Mediterranean burned scars from MODIS data. En Proceedings of the 5th International Workshop on Remote Sensing and GIS applications to Forest Fire Management: Fire Effects Assessment (de la Riva, J., Pérez-Cabello, F. y Chuvieco, E., Eds.). Universidad de Zaragoza, GOFC-GOLD, EARSeL, Zaragoza, 193-198.

PÉrez, B. y Moreno, J.M. (1998). Methods for quantifying fire severity in shrublandfires. Plant Ecology 139: 91-101.

Roy, D., Frost, P.G.H., Justice, C.O., Landmann, T., Le RouX, J.L., Gumbo, K., Makungwa, S., Dunham, K., Du Toit, R., Mhwandagara, K., Zacarías, A., Tacheba, B., Dube, O.P., Pereira, J.M.C., Mushove, P., Morisette, J.T., SanthaNA VAnnan, S.K. y Davies, D. (2005a). The Southern Africa Fire Network (SAFNet) regional burned-area product-validation protocol. International Journal of Remote Sensing 97: 137-162. 
Roy, D.P., Jin, Y., Lewis, P.E. y Justice, C.O. (2005b). Prototyping a global algorithm for systematic fire-affected area mapping using MODIS time series data. Remote Sensing of Environment 97: 137-162.

Roy, D.P., Lewis, P.E. y Justice, C.O. (2002). Burned area mapping using multi-temporal moderate spatial resolution data - a bi-directional reflectance model-based expectation approach. Remote Sensing of Environment 83: 263-286.

Seshadri, K.S.V., RaO, M., Jayaraman, V., Thyagarajan, K. y Murthi, K.R.S. (2005). Resourcesat-1: A global multi-observation mission for resources monitoring. Acta Astronautica 57: 534-539.

Valcarce, F., Ramírez, J., Casanova, J.L., Calle, A. y De Santis, A. (2007). The next step of Remote Sensing services for operational forest fire-fighting within GMES. En $4^{a}$ Conferencia Internacional sobre Incendios Forestales, Wildfire 2007, Sevilla.

Verdú, F. (2007). Análisis espacial de área quemada: patrón y variación de los incendios forestales en España, 1991-2005. Tesina. Departamento de Geografía. Universidad de Alcalá, Alcalá de Henares. 